ARTIGO

\title{
Avaliação da implementação do Programa Nacional de Acesso ao Ensino Técnico e Emprego (Pronatec): um estudo de caso no município de Picuí-PB
}

Thiago da Silva Laurentino ${ }^{\text {a }}$ Jomária da Mata de Lima Alloufa ${ }^{\text {b }}$

\section{Resumo}

O estudo objetivou avaliar o processo de implementação do Pronatec no IFPB campus Picuí, a partir da visão dos gestores, baseando-se na Abordagem Sequencial de Políticas Públicas e utilizando a metodologia da Anatomia do Processo Geral de Implementação. Trata-se de uma pesquisa avaliativa, do tipo estudo de caso. Para coleta de dados foram utilizadas a pesquisa documental e a entrevista. Os dados foram analisados qualitativamente, através da Análise Documental e da Análise de Conteúdo. Foram identificadas fragilidades e potencialidades nos subprocessos de implementação. Identificaram-se como fragilidades: processos de divulgação que alcançaram públicos limitados; atrasos no repasse dos recursos financeiros; inexistência de capacitação dos servidores e de processos avaliativos internos. Como potencialidades identificaram-se: autonomia e descentralização nos processos decisórios; quantidade de recursos orçamentários; realização de processos seletivos dos implementadores e capacidades dos implementadores.

Palavras-chave: Políticas públicas. Avaliação. Implementação. Pronatec.

\section{Introdução}

No ano de 2011, através da Lei no 12.513 , o Governo Federal, na gestão da presidente Dilma Rousseff (2011-2016), criou o Programa Nacional de Acesso ao Ensino Técnico e Emprego (Pronatec), que tem como objetivo central

\footnotetext{
a Universidade Federal do Rio Grande do Norte - UFRN, Natal, RN, Brasil.

b Universidade Federal do Rio Grande do Norte - UFRN, Natal, RN, Brasil. 
democratizar o acesso à Educação Profissional e Tecnológica (EPT), priorizando o atendimento às pessoas em situação de vulnerabilidade social, através da oferta de cursos técnicos e profissionalizantes, em unidades da Rede Federal e das Redes Estaduais de EPT, unidades do Sistema S (Serviço Nacional de Aprendizagem Industrial - Senai, Serviço Social da Indústria - Sesi, Serviço Nacional de Aprendizagem Comercial - Senac, Serviço Social do Transporte - Sest, Serviço Social do Comércio Sesc, Serviço Nacional de Aprendizagem Rural Senar, Serviço Nacional de Aprendizagem do Transporte - Senat, Serviço Nacional de Aprendizagem do Cooperativismo - Sescoop e Serviço Brasileiro de Apoio às Micro e Pequenas Empresas - Sebrae) e Universidades Privadas (BRASIL, 2011).

De acordo com o Relatório de Avaliação da Execução, do Ministério da Transparência e Controladoria-Geral da União (BRASIL; 2018), no período de 2011 a 2016, foram realizadas 4.659.309 matrículas, principalmente nas instituições do Sistema S $(66,62 \%)$ e na Rede Federal de EPT $(15,31 \%)$, com uma execução financeira de aproximadamente 11,3 bilhões de reais. Considerando o volume de recursos investidos e a quantidade de instituições envolvidas na implementação do programa, diversos estudos vêm sendo desenvolvidos sobre diferentes aspectos da política nos últimos anos.

No que se refere, especificamente, à avaliação de processos, que são os estudos que dizem respeito à dimensão da gestão, realizados durante e sobre o processo de implementação da política (COHEN; FRANCO, 1993), podem-se mencionar os trabalhos de Silva, Campelo e Dias (2015) e Santos et al. (2016), que trataram da implementação do Pronatec em municípios do estado da Paraíba (João Pessoa e Guarabira) e os trabalhos de Silva, Pimentel e Finardi (2014); Contarine e Oliveira (2014); e Oliveira, Ferreira e Silva (2019) que trataram da implementação de cursos técnicos através do Pronatec, nos municípios de Serra/ES, de Belo Horizonte/MG e na Rede Estadual de ensino do Mato Grosso do Sul, respectivamente. Os estudos levantaram informações, a partir de diferentes metodologias e enfoques, sobre desafios e potencialidades do processo de implementação do Pronatec em instituições da Rede Federal de EPT, no Sistema S e em uma Rede Estadual de EPT. A evasão dos estudantes é a principal questão apresentada como desafio na maioria dos estudos. Outras informações sobre esses estudos serão apresentadas no decorrer do texto, comparando-as com informações obtidas na pesquisa que se apresenta.

Dessa forma, o presente estudo teve como objetivo avaliar o processo de implementação do Pronatec, a partir da visão dos gestores do programa no Instituto 
Federal de Educação, Ciência e Tecnologia da Paraíba - IFPB - campus Picuí. A pesquisa baseou-se na Abordagem Sequencial de Políticas Públicas e utilizou a metodologia da Anatomia do Processo Geral de Implementação, proposta por Draibe (2001). Os dados da pesquisa foram obtidos através de entrevistas e levantamento dos seguintes documentos: Lei n ${ }^{\circ}$ 12.513/2011, Cartilha Pronatec Brasil sem Miséria, Relatórios gerados pelo Sistema Nacional de Informações da Educação Profissional e Tecnológica (Sistec) ${ }^{1}$, Editais de seleção de técnicos e professores e relatórios de cumprimento do objeto.

No intuito de organizar as informações para o leitor, o texto se divide nas seguintes seções: a primeira, que oferece algumas conceituações sobre Políticas Públicas, o Ciclo de Políticas Públicas, Implementação e Avaliações de Processo; a segunda, que apresenta a metodologia da Anatomia do Processo Geral de Implementação; a terceira, que contextualiza informações sobre o Pronatec; a quarta, que apresenta o percurso metodológico da pesquisa; a quinta, que apresenta os resultados obtidos no estudo, realizando uma avaliação sobre o processo de implementação; e, finalmente, a sexta, que apresenta considerações finais, além de algumas sugestões que, oportunamente, poderiam contribuir para o enfrentamento das fragilidades diagnosticadas.

\section{Política pública e avaliação de processos}

Política Pública é uma diretriz elaborada para enfrentar um problema público, uma orientação à atividade ou passividade, que possui intencionalidade e resposta a um problema coletivamente relevante (SECCHI, 2013). Existe hoje uma diversidade de abordagens, teorizações e vertentes analíticas que buscam explicar os diversos processos de formulação e gestão das políticas públicas. Uma delas é a Abordagem Sequencial ou Ciclo de Políticas Públicas, que consiste na divisão das atividades dos governos em momentos, ou etapas sequenciais e interdependentes. Segundo Frey (2000), ao dividir o agir público em fases do processo político-administrativo de resolução de problemas, o Ciclo de Políticas Públicas acaba se revelando um modelo heurístico bastante interessante para análise da vida de uma política. Secchi (2013), ao realizar uma revisão de literatura sobre o ciclo de políticas públicas, apresenta um modelo composto por sete fases, quais sejam: Identificação do Problema, Formação da Agenda, Formulação das Alternativas, Tomada de Decisão, Implementação, Avaliação e Extinção.

Sistema do Ministério da Educação (MEC) de acesso restrito aos usuários. 
A implementação, objeto deste estudo, é a fase em que, vencidos os obstáculos inerentes à introdução da questão na agenda governamental, o governo mobiliza-se para construir a política em seus aspectos institucionais e organizacionais, através da elaboração de um planejamento fundamentado no diagnóstico da realidade que será alvo de intervenção (SIMAN, 2005) e compreende o processo entre as declarações formais da política e o resultado final alcançado, momento em que ocorrerem influências de diversas variáveis independentes, que apoiam, alteraram, ou obstruem o cumprimento dos objetivos originais da política (VAQUERO, 2007).

A fase de avaliação é uma etapa importante no ciclo das políticas públicas, para melhoria da eficiência do gasto público, da qualidade da gestão e do controle social (RAMOS; SCHABBACH, 2012), além de contribuir para o aperfeiçoamento do processo de formulação de políticas, programas e projetos, tornando mais responsável a definição de metas, e apontando a capacidade de resposta dos governos às necessidades dos cidadãos (RUA, 2012). Os processos avaliativos são deliberados, sistemáticos e complexos, orientado pelo método científico e de caráter público, incluindo necessariamente uma dimensão técnico-metodológica e outra dimensão política, ambas articuladas (SILVA, 2001) e envolvem diversos conceitos, tipologias e metodologias.

Dentre os tipos de avaliação, apresenta-se especificamente a realizada neste estudo, a avaliação de processos, que tem o foco no desenho, nas características organizacionais e no desenvolvimento do programa, buscando identificar os fatores facilitadores e os obstáculos que operam ao longo da implementação e que interferem no cumprimento das metas (DRAIBE, 2001). As avaliações de processos investigam de forma sistemática o desenvolvimento dos programas, acompanha seus processos internos, objetivando detectar possíveis defeitos, barreiras e obstáculos na implementação, além de gerar informações importantes para reprogramação da política (COSTA; CASTANHAR, 2003).

\section{Anatomia do Processo Geral de Implementação}

Draibe (2001) apresenta que a importância de se estudar a implementação está na possibilidade de visualizar, por meio de esquemas analíticos, as falhas e os obstáculos que acometem o processo de implementação, além de erros anteriores à tomada de decisão, como a má formulação de problemas ou de objetivos. Dessa forma, a autora propõe uma metodologia de avaliação, chamada de Anatomia do Processo Geral de Implementação, que consiste na avaliação de sistemas e subprocessos, quais sejam: 
- O Sistema Gerencial e Decisório, que consiste nas características da estrutura organizacional da instituição onde o programa é implementado (DRAIBE, 2001).

- Os Processos de Divulgação, que consistem nas formas de circulação das informações, entre os atores implementadores e os beneficiários (DRAIBE, 2001).

- Os Sistemas de Seleção, que são os tipos e critérios de seleção utilizados para escolher atores implementadores e/ou beneficiários do programa (DRAIBE, 2001).

- Os Sistemas de Capacitação que se referem a como os implementadores são treinados e as capacidades que possuem para colocar em prática as diretrizes do programa (DRAIBE, 2001).

- Os Sistemas Internos de Monitoramento e Avaliação, que são as formas, critérios e efeitos da avaliação e monitoramento (DRAIBE, 2001).

- Os Sistemas Logísticos e Operacionais, que se relacionam aos parâmetros de suficiência, ou seja, se as quantidades de recursos materiais, humanos, financeiros e de tempo são suficientes para a execução do programa (DRAIBE, 2001).

Apesar de os subsistemas estarem expostos separadamente, essa divisão tem fins didáticos e de organização das informações. Os subsistemas apresentam, entre eles, interligações e interdependências, podendo ser verificados aspectos de determinados subsistemas que interferem nos demais e no desempenho do programa como um todo.

\section{O Programa Nacional de Acesso ao Ensino Técnico e Emprego}

A política de educação profissional no Brasil passou por um significativo incremento, a partir do governo do presidente Lula (2003-2010), principalmente com a criação dos Institutos Federais de Educação, Ciência e Tecnologia, em 2008, e a criação de 214 novas escolas técnicas federais em todos os Estados brasileiros, entre os anos de 2003 a 2010 (CASSIOLATO; GARCIA, 2014). 
A expansão da educação profissional, o cenário de crescimento econômico e a demanda de mão de obra, por parte de diversos setores produtivos, sobretudo àqueles ligados à área tecnológica, além do número de jovens e adultos com baixo grau de escolarização, foram os fatores que justificaram a elaboração do texto da Lei de criação do Pronatec. Em 2010, a economia brasileira havia crescido 7,5\% (maior taxa em 24 anos) e em 2012, a taxa de desemprego chegava a apenas $6 \%$, o percentual de empregados era de $48,5 \%$, enquanto que em 2011 , $47,5 \%$ da população com mais de 15 anos tinha menos de oito anos de estudo (CASSIOLATO; GARCIA, 2014).

A Lei prevê a transferência de recursos financeiros às instituições de educação profissional e tecnológica, sendo as instituições que oferecem os cursos denominadas ofertantes, e as instituições que constatam a necessidade de oferta e solicitam os cursos (Ministérios, Secretarias estaduais e municipais, entre outras), denominadas demandantes. Os cursos são solicitados de acordo com as potencialidades dos segmentos produtivos das regiões e do público a que se pretende atender.

\section{Percurso metodológico}

Trata-se de uma pesquisa avaliativa que compreende uma forma de valoração sistemática e aplicação de procedimentos para fazer julgamentos sobre o programa, no intuito de subsidiar o processo de tomada de decisão (ARREAZA; MORAES, 2010). O trabalho apresenta o estudo de caso do processo de implementação do Pronatec no campus Picuí do IFPB, no recorte temporal de 2012 a 2015.

Os sujeitos da pesquisa foram os três gestores do Pronatec no campus Picuí, que estiveram à frente do programa durante o período estudado. A coleta de dados foi realizada mediante Pesquisa Documental e Entrevistas. Os documentos acessados foram a Lei 12. 513/2011, a Cartilha Pronatec Brasil sem Miséria, que oferece instruções aos implementadores do programa, os Relatórios gerados pelo Sistec, os Editais de seleção de técnicos e professores e os relatórios de cumprimento do objeto, os quais sintetizavam as ações realizadas nas ofertas de cursos. Foram realizadas entrevistas semiestruturadas com os gestores, mediante autorização dos entrevistados, com assinatura do Termo de Consentimento Livre e Esclarecido (TCLE), e a anuência da Direção-Geral do campus.

Como técnica de análise das entrevistas, foi utilizada a análise de conteúdo, proposta por Bardin (2011), que consiste no conjunto de instrumentos de cunho metodológico que se aplicam a discursos, utilizando-se da categorização por caixas, ou seja, distribuindo os elementos encontrados em função da teoria. 
Quanto aos dados obtidos através dos documentos, foi utilizada a técnica de Análise Documental, que consiste na identificação, verificação e apreciação dos documentos, com finalidade de descrever o conteúdo de forma diferente dos originais (SOUZA; KANTORSKI; LUIS, 2011). Os dados obtidos foram agrupados em categorias temáticas correspondentes ao modelo de avaliação de implementação proposto por Draibe (2001).

\section{Avaliando os Subprocessos e Sistemas da Implementação do Pronatec no IFPB - campus Picuí}

O município de Picuí está localizado no interior do estado da Paraíba, possui 18.222 habitantes, taxa de urbanização de $66,5 \%$ (IBGE, 2011) e Índice de Desenvolvimento Humano de 0,608 (PNUD, 2010). De acordo com informações do Relatório de Informações Sociais do Programa Bolsa Família e Cadastro Único (CadÚnico), divulgado pelo Ministério de Desenvolvimento Social e Combate à Fome (MDS), Picuí possuía, em dezembro de 2016, 4.157 famílias inscritas no CadÚnico, com renda mensal de até meio salário mínimo por pessoa, totalizando 12.590 pessoas cadastradas. Das famílias inscritas, 78,57\% possuíam uma renda familiar per capita igual ou inferior a $\mathrm{R} \$ 85,00$. Esses dados demonstram a expressividade do número de potenciais beneficiários do Pronatec no município, tendo em vista que as pessoas em situação de vulnerabilidade social são o público-alvo do programa e que a inscrição no CadÚnico é condição de acesso aos cursos.

O campus Picuí do IFPB, de acordo com o Plano de Desenvolvimento Institucional -PDI 2010 - de 2014, iniciou suas atividades no ano de 2009 e oferece cursos técnicos, de graduação e de pós-graduação (IGPB, 2010). A implantação do Pronatec no IFPB ocorreu em janeiro de 2012, sendo o campus Picuí responsável, inicialmente, apenas pela oferta do Curso Técnico Concomitante ao Ensino Médio em Informática, que consistia na oferta de formação na área técnica em informática, para alunos que estivessem cursando o Ensino Médio.

Segundo relato das entrevistas, a decisão inicial de adesão ao Pronatec partiu da Reitoria do Instituto. No entanto, os gestores também relataram que a imposição não foi exclusividade nos campi do IFPB, pois o Pronatec surgiu como uma obrigação para toda a Rede Federal de EPT. No estudo realizado, Oliveira, Ferreira e Silva (2019) apontam que os gestores estaduais foram induzidos a aderir ao Pronatec para não perderem a possibilidade de financiamento da educação profissional. 
Desde a implantação, em 2012, até o ano de 2015, segundo dados do Sistec, foram ofertados, no campus Picuí, 770 vagas em 23 cursos de Formação Inicial e Continuada (FIC) e 40 vagas no curso Técnico em Informática. Os cursos FIC possuem carga horária mínima de 160 horas, ofertados em média de três a quatro meses. O total de beneficiários que concluíram os cursos FIC foi de 618, o que corresponde a $80,26 \%$ do total de vagas ofertadas. No caso do curso Técnico em Informática, apenas quatro estudantes concluíram o curso, o que corresponde somente a $10 \%$ do total de vagas ofertadas. De acordo com os gestores, o alto índice de evasão no curso Técnico em Informática ocorreu devido à implantação do Ensino Médio em período integral na escola parceira, que, inicialmente, funcionava em apenas um turno. Outra questão apontada como causa da evasão, foi a dificuldade, por boa parte dos alunos, de assimilarem o conteúdo das disciplinas técnicas, os quais requeriam conhecimentos prévios de Matemática, Física e Lógica. $\mathrm{O}$ alto índice de evasão em cursos técnicos concomitantes ao Ensino Médio, ofertados por instituições distintas, também foi verificado em outros estudos (OLIVEIRA; FERREIRA; SILVA, 2019; CONTARINE; OLIVEIRA, 2014; SILVA; PIMENTEL; FINARDI, 2014), principalmente por não haver uma articulação pedagógica entre os cursos, dificultando a construção do conhecimento e, em muitos momentos sobrecarregando os estudantes com conteúdo, atividades e avaliações.

Outro ponto a destacar é a diferença entre o número de vagas em cursos técnicos e em cursos FIC. Uma sobreposição do número de cursos FIC seria natural, por haver a necessidade de atendimento das pessoas que não possuíam o nível de escolaridade suficiente para o ingresso em cursos técnicos, já que $84,44 \%$ da população de Picuí não tinha alcançado o Ensino Médio completo, segundo Censo do Instituto Brasileiro de Geografia e Estatística - IBGE (2010), e pelo fato da execução dos cursos técnicos demandar da instituição maior quantidade de recursos (laboratórios, docentes, estrutura administrativa). No entanto, a discrepância entre o número de vagas ofertadas nas duas modalidades, sugere o comprometimento do alcance de dois objetivos do Pronatec: o de expansão, interiorização e democratização do acesso à Educação Profissional, tanto em nível técnico, quanto de qualificação profissional e o de contribuir para a melhoria da qualidade do Ensino Médio público, em articulação com a Educação Profissional. A oferta majoritária de cursos FIC não contribui para o aumento da escolaridade da população, nem para a articulação entre o Ensino Médio e Educação Profissional.

\subsection{Sistema Gerencial e Decisório}

O IFPB criou uma estrutura organizacional específica para a realização das atividades do Pronatec. Existia uma Coordenação-Geral, ligada à Pró-Reitoria de 
Extensão, responsável por dar suporte e orientar os campi na execução do Pronatec. Nos campi, há uma Coordenação Adjunta do Pronatec. Após a implantação do Pronatec no campus Picuí, foram nomeados uma Coordenadora Adjunta Acadêmica e um Coordenador Adjunto Financeiro. Em 2015, com a redução do programa e dos recursos orçamentários, o Pronatec passou a ter apenas um Coordenador Adjunto, acumulando as funções administrativas acadêmicas e financeiras.

$\mathrm{O}$ número de técnicos que trabalharam no programa, também variou durante o período avaliado. A equipe era composta por Supervisores, Orientadores e Apoio Administrativo Acadêmico e Apoio Administrativo Financeiro. A Tabela apresenta a evolução do número de pessoal no Pronatec entre os anos de 2012 a 2015.

Os técnicos do Pronatec no campus Picuí eram servidores efetivos do IFPB, os quais foram selecionados através de Edital para atuarem no programa. Os Coordenadores Adjuntos eram nomeados pela Direção-Geral do campus. Todos os integrantes da equipe possuíam curso superior, apesar de não ser uma exigência na seleção para as funções de Apoio Administrativo. Apenas em 2014, após sucessivas publicações de Editais internos para o encargo de Apoio Administrativo-Acadêmico, foi publicado um Edital de seleção externa, passando a equipe ser composta, naquele ano, por um componente não servidor efetivo do instituto.

De acordo com os gestores, existia autonomia nos processos decisórios por parte da coordenação adjunta, dentro do que a legislação determinava. Por exemplo, a indicação dos cursos a serem ofertados era realizada pelos demandantes, mas a coordenação adjunta decidia sobre a oferta dos cursos, considerando as condições

Tabela. - Evolução do Quantitativo de Técnicos do Pronatec no Ccampus Picuí entre os anos de 2012 a 2015.

\begin{tabular}{lcccc}
\hline \multirow{2}{*}{ Função } & \multicolumn{4}{c}{ Ano } \\
\cline { 2 - 5 } & $\mathbf{2 0 1 2}$ & $\mathbf{2 0 1 3}$ & $\mathbf{2 0 1 4}$ & $\mathbf{2 0 1 5}$ \\
\hline Coordenadores Adjuntos & 2 & 2 & 2 & 1 \\
Supervisores & 1 & 1 & 2 & 1 \\
Orientadores & - & 2 & 2 & 1 \\
Apoio Administrativo-Acadêmico & - & 2 & 2 & 1 \\
Apoio Administrativo-Financeiro & 1 & 1 & - & - \\
\hline TOTAL & 4 & 8 & 8 & 4 \\
\hline
\end{tabular}

Fonte: Informações obtidas através das entrevistas e dos editais de seleção (2016). 
e a estrutura que possuíam. Percebeu-se também um nível de descentralização nas tomadas de decisão, considerando que os cursos ofertados eram fruto de um processo de negociação entre demandantes e ofertante.

A criação de uma estrutura organizacional específica para o Pronatec dentro da Reitoria e nos campi do IFPB proporcionou um direcionamento do trabalho, principalmente quando a Coordenação-Geral desempenha um papel de orientação e suporte às coordenações adjuntas locais, atendendo o que Siman (2005) considera importante no processo de implementação: arranjos organizacionais e institucionais que articulem os interesses, com mecanismos de coordenação e controle dos atores envolvidos.

Outro ponto a ser destacado é o fato de a maioria dos agentes implementadores serem servidores efetivos do IFPB e, no caso dos técnicos e professores, o fato de serem selecionados através de Editais, o que de certa forma garante que possuam experiência com educação profissional, ao considerar critérios como qualificação profissional e experiência na área.

\subsection{Processos de divulgação e informação}

As primeiras informações sobre o programa foram passadas, presencialmente, por servidores da Coordenação-Geral, para os implementadores e os representantes das instituições demandantes. Inexistiam informações sobre como os recursos seriam repassados aos campi, e as informações sobre o programa eram obtidas principalmente através do site.

A divulgação do programa para os primeiros beneficiários foi realizada presencialmente, através de reunião com o público-alvo. Posteriormente, os cursos foram divulgados através de rádios locais. Apesar da seleção dos beneficiários ser uma responsabilidade da instituição demandante, a equipe do campus costumava auxiliar na divulgação das vagas. Todas as vagas ofertadas eram ocupadas, no entanto, muitos beneficiários participavam de mais de um curso, o que sugere uma restrição no acesso do público-alvo ao programa.

Quanto aos processos de divulgação voltados à seleção de pessoal, destacase a importância do recrutamento de profissionais para o desempenho das atribuições técnicas e de docência, em quantidade suficiente e com as competências necessárias. Os editais de seleção de pessoal administrativo e docente eram divulgados através do site do IFPB e de e-mail enviado aos servidores do campus. De acordo com os gestores, houve dificuldades na seleção de professores para algumas disciplinas. A inexistência de docentes 
aprovados nos processos seletivos demandava a publicação de outros editais, o que muitas vezes atrasava a oferta de algumas disciplinas. Essa dificuldade no recrutamento de profissionais também sugere uma restrição nos processos de divulgação dos editais, que estava limitada à comunidade do IFPB e ao site da instituição, o que de certa forma explica a participação predominante de servidores efetivos na implementação do programa.

Draibe (2001) trata da importância de se investigar a qualidade das informações divulgadas sobre o programa e verificar o quanto essas informações são acessíveis ao público-alvo. A divulgação mais ampla dos processos seletivos para técnicos e professores contribuiria para o melhor funcionamento dos cursos, uma vez que haveria possibilidades mais amplas de profissionais a serem contratados a tempo da realização dos cursos.

\subsection{Sistemas de Seleção}

Os sistemas de seleção que ocorreram durante a implementação do Pronatec no campus Picuí, envolveram dois públicos distintos: de beneficiários (alunos) e de agentes implementadores (técnicos e professores).

Os pré-requisitos para participação no programa, enquanto beneficiário, eram 1) ter pelo menos 16 anos de idade e 2) estar cadastrado, ou em processo de cadastramento, no CadÚnico. Além desses dois pré-requisitos, deveriam ter prioridade os inscritos em situação de extrema pobreza (com renda familiar per capita de até 70 reais) e os beneficiários do Programa Bolsa Família. A escolaridade dos beneficiários era apenas autodeclarada, não podendo haver exigência de comprovação, justamente para estimular a participação de pessoas que não tivessem condições de comprovação. O processo de seleção dos beneficiários do Pronatec era realizado pelas instituições demandantes.

No que diz respeito à seleção dos agentes implementadores, todas as seleções ocorreram através de Editais. Apenas os coordenadores foram nomeados pelo reitor, a partir da indicação dos diretores dos campi. Os trabalhadores do Pronatec, quando servidores públicos, recebiam remuneração adicional conforme quantidade de horas efetivamente dedicadas ao programa, fora da carga horária de trabalho nos cargos que ocupam. Os critérios de seleção variavam de acordo com a função desempenhada, mas envolviam, principalmente, a formação e a titulação acadêmica e a experiência na Educação Profissional. Os editais, via de regra, eram abertos apenas a servidores do IFPB. Não havendo a ocupação das vagas nessa seleção, outro edital era publicado, com possibilidade de inscrição de qualquer pessoa interessada, servidor ou não. 
As seleções para a função de professor ocorriam por disciplina, de acordo com a área de formação/atuação. Para atuação em cursos técnicos, era necessário ser professor da Rede Federal de EPT. Essa exigência não existia para os cursos FIC, que, geralmente, admitia professores que tivessem graduação na área da disciplina e, em alguns casos, o requisito era possuir um Curso Técnico. Segundo relato das entrevistas, houve flexibilização nos editais para seleção de professores, pois, em algumas áreas não era possível exigir formação de nível superior, sobretudo para disciplinas práticas de cursos como o de Pedreiro de Alvenaria, Garçom ou Costureiro, por exemplo. Para as disciplinas de caráter mais prático desses cursos, os professores deveriam ter experiência na área de atuação, o que passou a ser o pré-requisito em processos seletivos posteriores. Os candidatos à função de professor que não tivessem curso de licenciatura ou não tivessem experiência anterior na docência, além de participarem da avaliação curricular, participavam de uma prova didática, de caráter eliminatório. Como havia seleção de professores para cada uma das disciplinas de todos os cursos, muitas vezes o período entre a publicação do resultado final e a data definida para o início do curso era curto, necessitando de esforços da Coordenação Adjunta para garantir que houvesse candidatos aprovados em todas as disciplinas.

Pode-se considerar a seleção dos beneficiários pelas instituições demandantes um aspecto importante, no sentido em que essas instituições têm maior contato e conhecimento sobre o público-alvo do programa. A limitação do público alcançado, provavelmente, se deu por fragilidades nos processos de divulgação e inexistência de busca ativa de possíveis beneficiários. No que se refere à seleção dos implementadores, a priorização dos servidores efetivos valoriza os profissionais da organização, garante um grau de experiência prévia dos implementadores na educação profissional e possibilita um maior alinhamento do programa às demais atividades desenvolvidas no instituto. Por outro lado, a priorização dos servidores pode ser vista pelo público externo como um privilégio ou corporativismo. Quanto à seleção dos professores, se destaca como potencialidade a realização da prova didática, não se restringido à avaliação dos currículos, o que possibilita que os candidatos aprovados demonstrem condições mínimas necessárias para ministrar aulas dentro da proposta do programa. Outro ponto importante foi a flexibilização do critério de se possuir curso superior ou técnico. Algumas disciplinas realmente não tinham como ser ministradas por pessoas que não tivessem o conhecimento prático, o que tornaria os cursos demasiadamente teóricos e abstratos. A seleção de professores por grupos de disciplinas de áreas comuns poderia ser menos dispendiosa e contribuir para maior permanência dos docentes no programa. 


\subsection{Sistemas de capacitação}

Os dados coletados indicaram a inexistência de uma estratégia de capacitação para os agentes implementadores. De acordo com os gestores, os professores que atuavam no Pronatec não passavam por nenhum tipo de capacitação. Para os técnicos, ocorriam reuniões onde eram passadas informações sobre a execução do programa, e houve algumas capacitações específicas para orientadores e supervisores. Os gestores destacaram que muitas das atividades realizadas pela equipe do Pronatec foram aprendidas na prática, sem que houvesse uma orientação e que alguns dos procedimentos de organização foram criados no campus Picuí e, posteriormente, adotados pela Coordenação-Geral do Pronatec como orientação para os demais campi. Relatos como esses também existiram no estudo realizado por Silva, Campelo e Dias (2015), em outro campus da mesma instituição, onde as informações sobre o programa foram obtidas à medida que as atividades eram desenvolvidas.

Quando indagados se os agentes implementadores já possuíam as competências necessárias para atuação, ao iniciarem as atividades no Pronatec, os gestores, relatarem que as competências foram adquiridas durante a realização das atividades, sendo mais crítica a situação dos professores, que não tinham a mesma possibilidade de troca de informações que os técnicos, uma vez que os docentes eram selecionados para lecionar uma ou, no máximo, três disciplinas. Segundo Arretche (2001), os agentes implementadores precisam de fato conhecer e aceitar o programa, seus objetivos e regras, para não elegeram outras referências para a implementação e comprometerem a operacionalização e o alcance dos objetivos do programa.

\subsection{Sistemas logísticos e operacionais}

O Governo Federal, através do Fundo Nacional de Desenvolvimento da Educação (FNDE), era responsável por fazer os repasses financeiros à instituição ofertante. De acordo com as entrevistas e com os relatórios de cumprimento do objeto, a quantidade de recurso disponibilizado era de 10 reais por aluno, por hora de curso, conforme as Resoluções CD/FNDE n ${ }^{\circ}$ 23/2012, n 33/2012 e n ${ }^{\circ}$ 06/2013. Por exemplo, um curso que tivesse duração de 160 horas, com 40 vagas, teria disponibilizado $\mathrm{R} \$ 64.000,00$ de recurso orçamentário.

De acordo com os relatos das entrevistas, os recursos eram transferidos do FNDE para a Reitoria do IFPB, que, por sua vez, realizava a descentralização para os campi, ficando a responsabilidade pela gestão sob a Coordenação Adjunta do Pronatec. No entanto, como o ordenador de despesas dos campi dos 
Institutos Federais são os Diretores-Gerais, todos os processos de compras e pagamentos deveriam ter a ciência e o aval da Direção. Os recursos deveriam ser utilizados exclusivamente para pagamento de pessoal (gestores, técnicos e professores), pagamento de auxílios aos beneficiários (transporte, alimentação e material didático), pagamento de prestação de serviços contratados e de compras de material de consumo do programa, não sendo permitida a aquisição de material permanente.

No que se refere à quantidade de recurso orçamentário, na percepção dos gestores, se tratava de uma quantidade suficiente. Porém, foi afirmando que era recorrente $o$ atraso no repasse dos recursos financeiros, o que prejudicava o andamento das atividades, seja no pagamento dos auxílios aos beneficiários, seja no pagamento dos professores e técnicos. De acordo com Arretche (2001), é comum que, no processo de implementação, metas quantitativas sejam fixadas para cada período, conforme a previsão de disponibilidade orçamentária. No entanto, com frequência, o comportamento não esperado da economia influi na disponibilidade de recursos. Também foram relatados atrasos na disponibilização de materiais, devido atraso nos procedimentos de compras, provocado por falhas no planejamento e inexistência de equipe especializada para realizar os procedimentos licitatórios.

Outra atividade do programa era o acompanhamento dos beneficiários nos cursos, cabendo à instituição ofertante realizar os registros de frequência dos beneficiários no Sistec. A frequência dos alunos influenciava no pagamento dos auxílios, de oito reais por dia de presença, perfazendo uma média de 160 reais por mês, para viabilizar transporte e alimentação dos beneficiários. No entanto, ocorreram atrasos nos pagamentos, o que pode ter comprometido a permanência de alguns. $\mathrm{O}$ acompanhamento da frequência também era importante para o controle de evasão nos cursos, a fim de realizar intervenções preventivas.

O Pronatec também prevê a articulação das instituições demandantes e ofertantes, para o acesso dos beneficiários às políticas de trabalho, emprego e renda, como acesso ao microcrédito, economia solidária, microempreendedorismo individual e intermediação de mão de obra com mercado de trabalho. De acordo com o relato dos gestores, essa atividade foi comprometida, em função da quantidade de demandas que os técnicos possuíam e da ausência de capacitação que fornecesse instrumentos para efetivar essa articulação. Os gestores, apesar de considerarem positivo o trabalho desenvolvido pelos técnicos e professores, ressaltaram a quantidade insuficiente de pessoal em alguns momentos. 
Draibe (2001) coloca a importância de se verificar nos Sistemas Logísticos e Operacionais, tanto se a quantidade de recursos é suficiente, quanto se os recursos são disponibilizados dentro dos prazos necessários. Dessa forma, constata-se que, apesar da quantidade de recursos orçamentários serem percebidos pelos gestores como suficientes, atrasos nos repasses de recursos financeiros comprometeu a execução do programa. Outro ponto a se observar é a impossibilidade de aquisição de material permanente, o que revela o caráter temporário do programa, no sentido em que não prevê investimentos numa estrutura permanente para oferta da qualificação profissional. Também foram identificadas como fragilidades do processo de implementação no estudo de Silva, Campelo e Dias (2015), que dizem respeito ao atraso no repasse de recursos financeiros; as dificuldades nos processos licitatórios; comprometimento das atividades de acompanhamento pedagógico dos estudantes por falta de capacitação no programa e quantitativo insuficiente de pessoal; e a impossibilidade de aquisição de materiais permanentes, por exemplo, por inviabilizar a ampliação de laboratórios e ir de encontro aos objetivos do programa.

\subsection{Sistemas internos de monitoramento e avaliação}

Sobre os Sistemas internos de Monitoramento e Avaliação, foi mencionada a realização de acompanhamento, por parte do MEC, dos relatórios gerados através do Sistec, com informações sobre a quantidade de vagas ofertadas, de alunos matriculados e de concluintes. Outros procedimentos avaliativos eram realizados pela Coordenação-Geral do Pronatec no IFPB. O critério mais considerado nessa avaliação era a utilização dos recursos financeiros: conformidade na utilização dos recursos, dentro dos padrões estabelecidos nas normas do programa, e a quantidade de recurso não utilizada e devolvida ao FNDE.

Também foi mencionada a utilização de um procedimento de avaliação das disciplinas ministradas e das atividades da equipe administrativa. Eram aplicados formulários com os beneficiários ao final das disciplinas para avaliação dos professores e ao final do curso, para avaliação do trabalho da equipe administrativa.

Apesar de os beneficiários fornecerem dados sobre como julgavam a execução do programa, esses dados não eram utilizados em um processo de avaliação interno, nem discutidos com a equipe. A inexistência de uma estratégia de avaliação bem definida e a má utilização dos dados obtidos consistiram em fragilidades verificadas nos Sistemas Internos de Monitoramento e Avaliação. Contarine e Oliveira (2014) também mencionam que o monitoramento do programa no caso estudado em Belo Horizonte praticamente se restringia à avaliação dos dados gerados através do Sistec. 
Segundo Silva (2001), no Brasil a avaliação de programas sociais ainda é restrita ao mero controle de gastos, conforme pode ser verificado também no caso do Pronatec no campus Picuí. A preocupação com a conformidade na utilização dos recursos públicos é importante, porém, não é suficiente para garantir e eficácia da implementação. Segundo Draibe (2001), as avaliações internas durante o processo de implementação são realmente raras, restringindo-se a examinar os registros administrativos e coletando opiniões dos agentes implementadores.

\section{Considerações finais}

A avaliação do processo de implementação do Pronatec no campus Picuí, realizada através do modelo teórico-metodológico da Anatomia Geral do Processo de Implementação, demonstrou a complexidade do processo de implementação, considerando, principalmente, a diversidade do público de beneficiários atendidos, as peculiaridades do programa implementado numa instituição que já possuía uma tradição na oferta de educação profissional e a especificidade do vínculo que possuíam os agentes implementadores.

Identificadas algumas fragilidades em cada um dos Sistemas e Processos da Implementação do Pronatec no campus Picuí do IFPB, sugere-se algumas medidas que, oportunamente, poderiam contribuir para o melhoramento do processo de implementação:

- Realização de uma busca ativa dos beneficiários, em parceria com equipamentos de políticas públicas de educação, assistência social e de trabalho, emprego e renda, garantindo o alcance do público-alvo do programa;

- Ampliação dos processos de divulgação dos Editais de Seleção ao público externo ao IFPB, realizando a divulgação em Instituições de Ensino Superior e Técnico, em empresas com atividades no ramo dos cursos e entre os profissionais dos órgãos públicos do município de Picuí e das cidades circunvizinhas;

- Definição de uma estratégia de capacitação, destinada aos gestores, aos parceiros, aos técnicos e aos professores, apresentando os objetivos do programa, as atribuições de cada um dos atores envolvidos e os procedimentos a serem adotados;

- Definição de uma estratégia de avaliação interna, que permita a identificação de entraves e intervenções adequadas. 
O estudo contribuiu também para a verificação da aplicabilidade da metodologia de avaliação do processo de implementação proposta por Draibe (2011). Os sistemas e subprocessos da Anatomia do Processo Geral de Implementação possibilitam a compreensão e avaliação exequível de processos complexos que envolvem a implementação das políticas públicas.

Verifica-se a necessidade de estudos comparativos sobre a implementação do Pronatec entre as unidades da Rede Federal de EPT e outras instituições, como o Sistema S e as Universidadess Privadas. Os aspectos avaliados também não contemplam toda a diversidade de questões e aspectos a serem observadas no processo de implementação. 


\section{Implementation of Pronatec in the view of managers: $a$ case study}

\section{Abstract}

The objective of this study was to evaluate the process of implementation of Pronatec in the IFPB - Campus Picui, from the view of the managers, based on the Sequential Approach of Public Policies and using the methodology of the Anatomy of the General Process of Implementation (DRAIBE, 2001). The research is evaluative, of the case study type. For data collection, documentary research and interview were used. The data were analyzed qualitatively through Document Analysis and Content Analysis. Fragilities and potentialities were identified in the implementation sub-processes. We identified as fragilities: disclosure processes that reached limited audiences; delays in the transfer of financial resources; lack of training of public servant and of internal evaluation processes. As potentialities, were identified: autonomy and decentralization in decision-making processes; amount of budgetary resources; execution of selective processes for the implementers; capabilities of the implementers.

Keywords: Public policy. Evaluation. Implementation. Pronatec.

\section{Implementación del Pronatec en la visión de los gestores: un estudio de caso}

\section{Resumen}

El objetivo del estudio fue evaluar el proceso de implementación del Pronatec en el IFPB - Campus Picuí, a partir de la visión de los gestores, basándose en el Enfoque Secuencial de las Políticas Públicas y utilizando la metodología de la Anatomía del Proceso General de Implementación (DRAIBE, 2001). La investigación es evaluativa, del tipo estudio de caso. Para la recolección de datos se utilizaron la investigación documental y la entrevista. Los datos fueron analizados cualitativamente, a través del Análisis Documental y del Análisis de Contenido. Se identificaron fragilidades y potencialidades en los subprocesos de implementación. Se identificó como fragilidades: procesos de divulgación que alcanzaron públicos limitados; retrasos en el traspaso de los recursos financieros; la inexistencia de capacitación de los servidores y de procesos de evaluación interna. Como potencialidades se identificó: autonomía y descentralización en los procesos decisorios; cantidad de recursos presupuestarios; realización de procesos selectivos de los implementadores; capacidades de los implementadores.

Palabras clave: Política pública. Evaluación. Implementación. Pronatec. 


\section{Referências}

ARREAZA, A. L. V.; MORAES, J. C. Contribuição

teórico-conceitual para pesquisa avaliativa no contexto de

vigilância da saúde. Ciência e Saúde Coletiva,

Rio de Janeiro, v. 15, n. 5, p. 2627-38, ago. 2010.

https://doi.org/10.1590/S1413-81232010000500037

ARRETCHE, M. T. S.. Uma contribuição para fazermos avaliações menos ingênuas. In: BARREIRA, M. C. R.; CARVALHO, M. C.B. (OrgS.).

Tendências e perspectivas na avaliação de políticas sociais. São Paulo:

IEE/PUC-SP, 2001. p. 43-56.

BARDIN, L. Análise de conteúdo. Lisboa: Edições 70, 2011.

BRASIL. Lei $\mathrm{N}^{\mathrm{o}} 12.513$, de 26 de outubro de 2011. Institui o Programa Nacional de Acesso ao Ensino Técnico e Emprego (Pronatec), e dá outras providências. Diário Oficial da União, 27 out. 2011.

. Ministério da Transparência e Controladoria-Geral da União. Relatório de avaliação da execução de programa de governo $N^{\circ} 79$ : apoio à formação profissional, científica e tecnológica. Brasília, DF, 2018.

CASSIOLATO, M. M. M. C.; GARCIA, R. C. PRONATEC: múltiplos arranjos e ações para ampliar o acesso à educação profissional. Rio de Janeiro: IPEA, 2014.

COHEN, E.; FRANCO, R. Avaliação de projetos sociais. Petrópolis, RJ: Vozes, 1993.

CONTARINE, M. L. M.; OLIVEIRA, M. A. M. Pronatec: estudo de caso realizado em um curso técnico de nível médio, em Belo Horizonte. Boletim Técnico do Senac, Rio de Janeiro, v. 40, n. 1, p. 108-27, jan/abr. 2014.

COSTA, F. L.; CASTANHAR, J. C. Avaliação de programas públicos: desafios conceituais e metodológicos. Revista de Administração Pública, Rio de Janeiro, v. 37, n. 5, p. 969-92, set/out. 2003.

DRAIBE, S. M. Avaliação de implementação: esboço de uma metodologia de trabalho em políticas. In: BARREIRA, M. C. R.; CARVALHO, M. C.B. (Orgs.). Tendências e perspectivas na avaliação de políticas sociais. São Paulo: IEE/PUC-SP, 2001. p. 13-42. 
FREY, K. Políticas públicas: um debate conceitual e reflexões referentes à prática da análise de políticas públicas no Brasil. Planejamento e Políticas Públicas, Brasília, n. 21, p. 211-59, jun, 2000.

INSTITUTO BRASILEIRO DE GEOGRAFIA E ESTATÍSTICA - IBGE. Sinopse do censo demográfico 2010. Rio de Janeiro, RJ, 2011.

INSTITUTO FEDERAL DE EDUCAÇÃO, CIÊNCIA E TECNOLOGIA DA PARAÍBA - IFPB. Programa de desenvolvimento institucional 2010-2014. João Pessoa, PB, 2010.

OLIVEIRA, A. D.; FERREIRA, V. A.; SILVA, C. M. S. Implications of concomitance in technical education financed by Pronatec in the Mato Grosso do Sul State education network (2012-2015). Ensaio: Avaliação e Políticas Públicas em Educação, Rio de Janeiro, v. 27, n. 103, p. 406-25, abr.jun. 2019. https://doi.org/10.1590/s0104-40362019002701715

PROGRAMA DAS NAÇÕES UNIDAS PARA O DESENVOLVIMENTO PNUD. Ranking IDH 2010. Brasília, DF, 2010.

RAMOS, M. P.; SCHABBACH, L. M. O estado da arte da avaliação de políticas públicas: conceituação e exemplos da avaliação no Brasil. Revista de Administração Pública, Rio de Janeiro, v. 46, n. (5), p. 1271-1294, set./out, 2012. https://doi.org/10.1590/S0034-76122012000500005

RUA, M. G. Politicas públicas. Florianópolis, SC: Departamento de Ciências da Administração/UFSC, 2012.

SANTOS, F. N. et al. Avaliando o Pronatc no IFPB: um estudo sobre implementação. Revista Uniabeu, Belford Roxo, v. 9, n. 21, p. 88-106, jan./abr. 2016.

SECCHI, L. Políticas públicas: conceitos, esquemas de análise, casos práticos. 2a ed. São Paulo, SP: Cengage Learning, 2013.

SILVA, C. R.; PIMENTEL, B. R.; FINARDI, K. R. Refletindo sobre evasão em cursos técnicos do Pronatec. Unopar Cientifica: Ciências Humanas e Educação, Londrina, v. 15, n. 3, p. 239-47, Out. 2014.

SILVA, M. C. S.; CAMPELO, M. E. C. H.; DIAS, M. C. Diretrizes da Educação Profissional Brasileira: propostas e desafios na implementação do PRONATEC. Revista Internacional de Organización Educativa y Liderazgo, Champaign, v. 2, n. 1, p. 23-36, 2015. 
SILVA, M. O. S. Avaliação de políticas e programas sociais: aspectos conceituais e metodológicos. In: . (Org). Avaliação de políticas e programas sociais: teoria e prática. São Paulo, SP: Veras, 2001. p. 37-93.

SIMAN, A. M. Políticas públicas: a implementação como objeto de reflexão teórica e como desafio prático. Belo Horizonte, MG: UFMG, 2005.

SOUZA, J.; KANTORSKI, L. P.; LUIS, M. A. V. Análise documental e observação participante na pesquisa em saúde mental. Revista Baiana de Enfermagem, Salvador, v. 25. n. 2, p. 221-228, mai/ago. 2011.

VAQUERO, Benjamim Revuelta. La implementación de políticas públicas. Dikaion, Chia, v. 21, n. 16, p. 135-56, nov. 2007.

\section{Informações dos autores}

Thiago da Silva Laurentino: Mestre em Gestão Pública pela UFRN. Psicólogo na Faculdade de Ciências da Saúde do Trairi, da mesma universidade.

Contato: thiagopsic@yahoo.com.br

iD https://orcid.org/0000-0001-8816-1068

Jomária da Mata de Lima Alloufa: Docente Permanente do Programa de Pós-graduação em Gestão Pública e Programa de Pós-graduação em Administração, da UFRN. Doutora em Ciências da Educação pela Université de Paris X, Nanterre.

Contato: jalloufa@yahoo.com.br

iD https://orcid.org/0000-0003-4935-0039 